\title{
Recent Development of Techniques and Devices in Colorectal Endoscopic Submucosal Dissection
}

\author{
Hiroya Mizutani', Satoshi Ono ${ }^{1}$, Daisuke Ohki ${ }^{1}$, Chihiro Takeuchi ${ }^{1}$, Seiichi Yakabi', Yosuke Kataoka ${ }^{1}$, Itaru Saito ${ }^{2}$, \\ Yoshiki Sakaguchi', Chihiro Minatsuki', Yosuke Tsuji', Keiko Niimi' ${ }^{2}$, Shinya Kodashima', Nobutake Yamamichi', \\ Mitsuhiro Fujishiro, ${ }^{1,2}$ and Kazuhiko Koike ${ }^{1}$ \\ Department of ${ }^{1}$ Gastroenterology, ${ }^{2}$ Endoscopy and Endoscopic Surgery, Graduate School of Medicine, The University of Tokyo, Tokyo, Japan
}

Colorectal endoscopic submucosal dissection (ESD) is now a well-established endoscopic treatment for early-stage colorectal neoplasms, especially in Asian countries, including Japan. Despite the spread of colorectal ESD, there are still situations in which achieving successful submucosal dissection is difficult. Various novel techniques and devices have been developed to overcome these difficulties, and past reports have shown that some of these strategies can be applied to colorectal ESD. We review several recent developments in the field. The techniques reviewed include the pocket creation method and traction methods and the devices reviewed include the overtube with balloon and electrosurgical knives with water-jet function. These improved techniques and devices can facilitate safer, more reliable ESDs and expand its applicability and acceptability all over the world. Clin Endosc 2017;50:562-568

Key Words: Colorectal endoscopic submucosal dissection; Pocket creation method; Traction method; Overtube with balloon; Electrosurgical knives with water-jet function

\section{INTRODUCTION}

Endoscopic submucosal dissection (ESD) was initially developed as an advanced technique in therapeutic endoscopy for superficial gastric neoplasms. ${ }^{1,2}$ This technique can provide en bloc resection of gastrointestinal mucosal lesions regardless of size. This enables accurate histological assessments and, as a result, appropriate clinical decision-making and management; including indications for additional treatment after resection. Because of its efficacy and utility, ESD has been used to treat neoplasms in other digestive organs, including the esophagus, duodenum, colon, and rectum. Recently,

Received: July 4, 2017 Revised: September 21, 2017

Accepted: October 20, 2017

Correspondence: Satoshi Ono

Department of Gastroenterology, Graduate School of Medicine, The University of Tokyo, 7-3-1, Hongo, Bunkyo-ku, Tokyo 113-0033, Japan

Tel: +81-3-3815-5411, Fax: +81-3-5800-8806, E-mail: satoshi-tky@umin.ac.jp

(cc) This is an Open Access article distributed under the terms of the Creative Commons Attribution Non-Commercial License (http://creativecommons.org/ licenses/by-nc/3.0) which permits unrestricted non-commercial use, distribution, and reproduction in any medium, provided the original work is properly cited. colorectal ESD has become increasingly widespread and sophisticated among expert endoscopists and their institutions, especially in Asian countries. ESD is now a well-established endoscopic treatment for colorectal neoplasms with a high cure rate and low complication rate after en bloc resections. ${ }^{3,4}$ Despite these achievements, there still remain some situations in which using ESD is difficult, even for experienced endoscopists. Difficulty can arise because of thin colorectal walls, poor endoscopic maneuverability, submucosal fibrosis, and other factors. Recently, several new techniques and devices have been developed to overcome these difficulties and to facilitate effective ESD in such challenging situations.

\section{NEW TECHNIQUES}

\section{Pocket creation method}

The pocket creation method (PCM) is a novel strategy of colorectal ESD, used especially for large laterally spreading tumors (LSTs). ${ }^{5,6}$ In the PCM procedure, after submucosal injection, an initial mucosal incision of minimal length is made, 


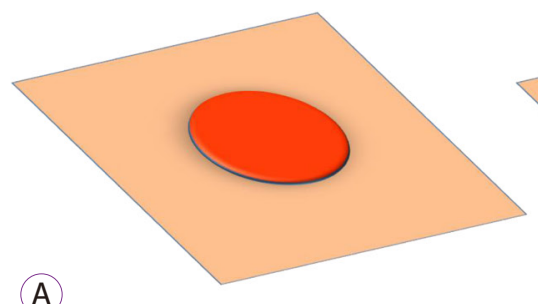

(A)

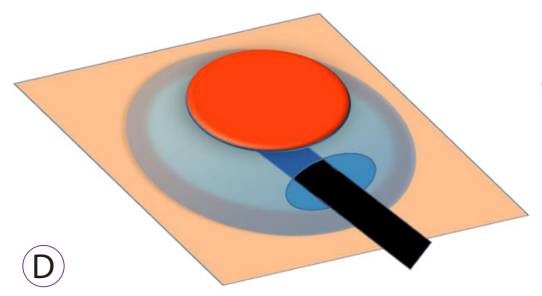

(B)

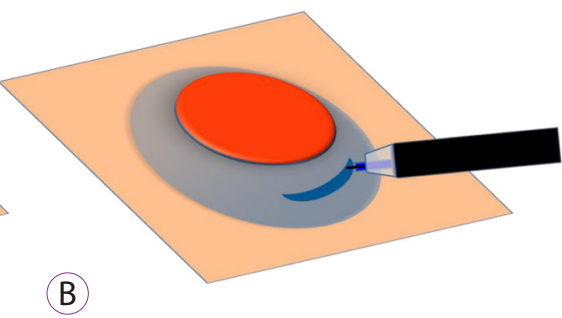

(C)

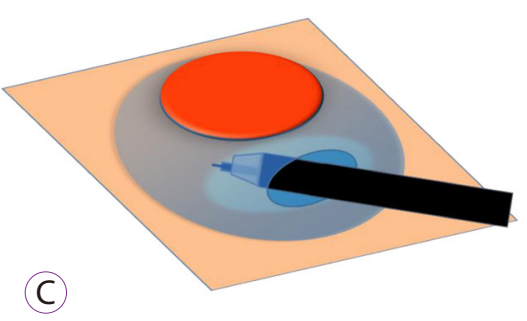

(E)

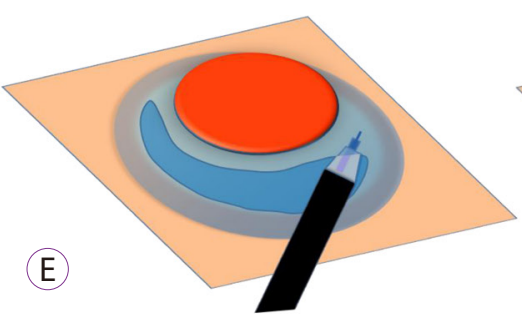

Fig. 1. Pocket creation method. (A) A colon tumor, such as a laterally spreading tumor. (B) A minimal mucosal incision is performed after submucosal injection. (C, D) The endoscope is inserted into the submucosal layer from the initial incision and submucosal dissection is performed in such a way as to make a pocket under the lesion. $(E, F)$ Finally, incisions are made around the lesion to complete en bloc resection of the remaining mucosa.

then the submucosal dissection is performed to make a large pocket in the submucosal layer under the lesion by inserting the tip of the endoscope through the initial incision using a small-caliber-tip transparent hood and needle-type knife. Subsequently, additional mucosal incisions are made all around the lesion and the remaining submucosal tissues are dissected (Fig. 1). This differs from a conventional colorectal ESD where the mucosal incision is suitably lengthened in accordance with the needs of the submucosal dissection. The PCM provides a safe and efficient dissection because the minimal incision can keep the submucosal layer thick and relatively easy to approach during the operation by preventing dispersion of the injected fluid. The operator using the PCM can visualize the submucosal layer and the muscular layer even in situations with poor endoscopic maneuverability because the tip of the endoscope inserted into the pocket can, by itself, facilitate tissue traction. Sakamoto et al. ${ }^{7}$ reported the efficacy of the PCM for colorectal LSTs, non-granular type. In that study the en bloc resection rate in the PCM group was significantly higher than in the conventional ESD group (100\% [73/73] vs. $92 \%$ [49/53], $p=0.03)$ with a lower perforation rate $(0 \%[0 / 73]$ vs. $4 \%$ $[2 / 53], p=0.18$ ), and a shorter procedural time (median [interquartile range], 19 [13-24] $\mathrm{mm}^{2} / \mathrm{min}$ vs. 14 [10-22] $\mathrm{mm}^{2} / \mathrm{min}$, $p=0.03$ ).

\section{Traction method}

In cases of colorectal ESD, even well-trained endoscopists can be faced with challenging situations where it is difficult to obtain good visualization of the submucosal layer because of, among other reasons, a narrow colorectal lumen, angulation of the colon, or poor maneuverability of the endoscope. The traction method is one of the techniques used to overcome these difficulties by generating counter-traction of the targeted lesions, thereby facilitating submucosal visualization. The traction force is applied with devices including clips, strings, snares, or grasping forceps. Several kinds of traction methods for colorectal ESD have been reported, such as the external forceps method, ${ }^{8-10}$ the clip-with-line method, ${ }^{11-14}$ the clip-andsnare method (CSM), ${ }^{15-17}$ and the clip-with-loops method. ${ }^{18-23}$ These methods are shown in Fig. 2.

\section{EXTERNAL FORCEPS METHOD}

Imaeda et al. ${ }^{8-10}$ reported the efficacy of an external forceps method for both gastric ESD and rectal ESD. After the mucosal circumferential incision is made, a bending biopsy forceps is held outside of the endoscope, being grasped with the grasping forceps which is inserted through the working channel of the endoscope. Then, after the bending forceps is delivered to the lesion, it can grasp the edge of the lesion and produce multi-directional traction by pulling, pushing, or bending. The application of this method is, however, limited to rectal neoplasms because of the technical difficulty in delivering the forceps. 

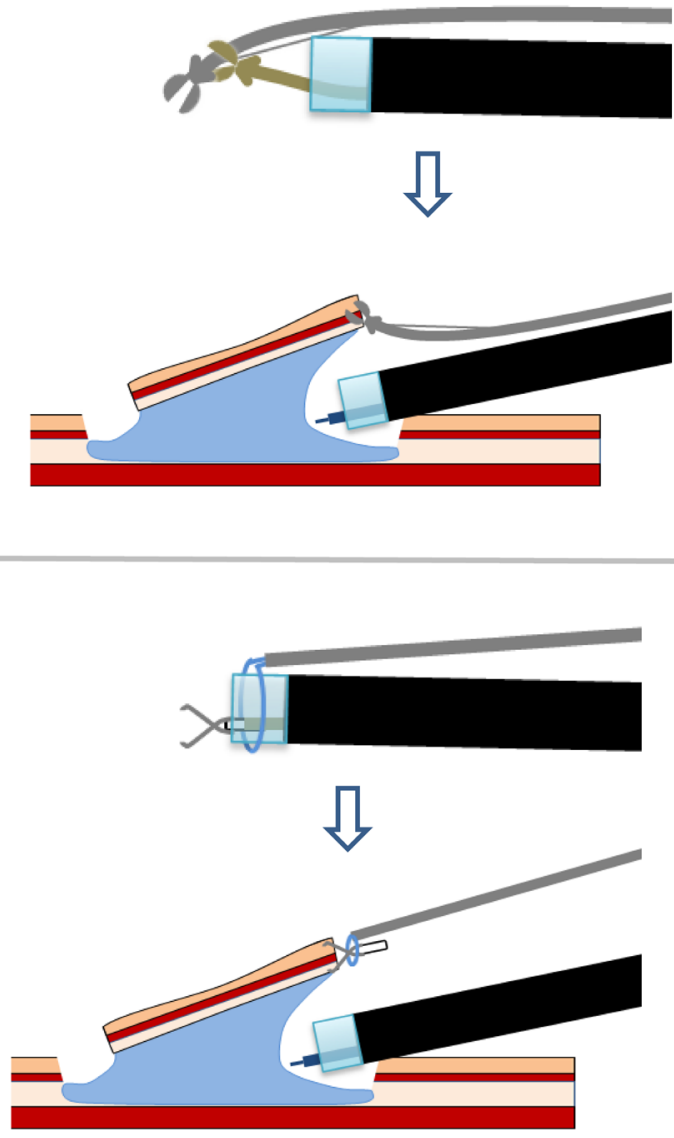

(C)

Fig. 2. Traction methods. (A) External forceps method. (B) Clip-with-line method. (C) Clip-and-snare method with a pre-looping technique. (D) Clip-with-loops method.

\section{CLIP-WITH-LINE METHOD}

The clip-with-line method was initially introduced as a traction method for gastric ESD. Later, its feasibility for esophageal ESD was suggested by Oyama ${ }^{11,12}$ A clip, with a silk line tied on its arm, is attached to the tip of the clip applicator device and inserted through the working channel. The endoscope, with the line along the outside of the scope, is inserted. Then, the clip with the line is attached to the edge of the lesion. Traction can be produced by pulling the line gently, thus achieving sufficient visualization of the submucosal layer to identify an accurate cutting line. This can be a simple and convenient method, however, it is somewhat laborious to apply to lesions in the proximal colon because it requires withdrawal and reinsertion of the endoscope. Yamasaki et al. ${ }^{13,14}$ reported that their modified clip-with-line method does not need withdrawal and reinsertion, and is feasible and safe for colorectal ESD.

\section{CLIP-AND-SNARE METHOD WITH A PRE-LOOPING TECHNIQUE}

The CSM with a pre-looping technique (CSM-PLT) was reported as an improved procedure derived from the CSM. ${ }^{15,16}$ The traction can be controlled with a snare that grasps a clip anchored on the edge of the lesion. In the conventional CSM, the snare is delivered to the clip using a grasping forceps inserted through the working channel. On the other hand, in CSM-PLT, the snare is pre-looped and fixed around the transparent cap attached to the tip of the endoscope, and then delivered with the scope reinsertion. This allows for an easier snare delivery, although an overtube is required for deep colon lesions. Yamada et al. ${ }^{17}$ suggested that the CSM-PLT can enable effective and safe colorectal ESD with a lower rate of adverse events and a shorter procedure time. 


\section{CLIP-WITH-LOOPS METHOD}

Several kinds of novel traction methods using a loop or loops connected to a clip, such as an S-O clip, ${ }^{18-20}$ loops attached to a rubber band, ${ }^{21}$ latex-band, ${ }^{22}$ or ring-shaped thread $^{23}$ have been reported for colorectal ESD (hereafter called the "clip-with-loops method"). The key feature of the clip-with-loops method is that counter traction is generated using loops, one side of which is attached to the edge of the lesion with a clip, and the other side is attached to the opposite side of the colonic wall (Fig. 3). These methods have a major advantage in that they do not require withdrawal and reinsertion of the endoscope because the clip-with-loops can be delivered through the working channel making it more favorable for lesions in the deep colon. Prospective controlled trials of the clip-with-loops method for colorectal ESD were reported by Ritsuno et al. using the S-O clip, ${ }^{20}$ and by Mori et al. using the ring-shaped thread. ${ }^{23}$ Both trials successfully demonstrated significantly reduced procedure time in the clip-with-loops group compared with the conventional ESD group while still achieving an equally high en bloc resection rate and no severe complications.
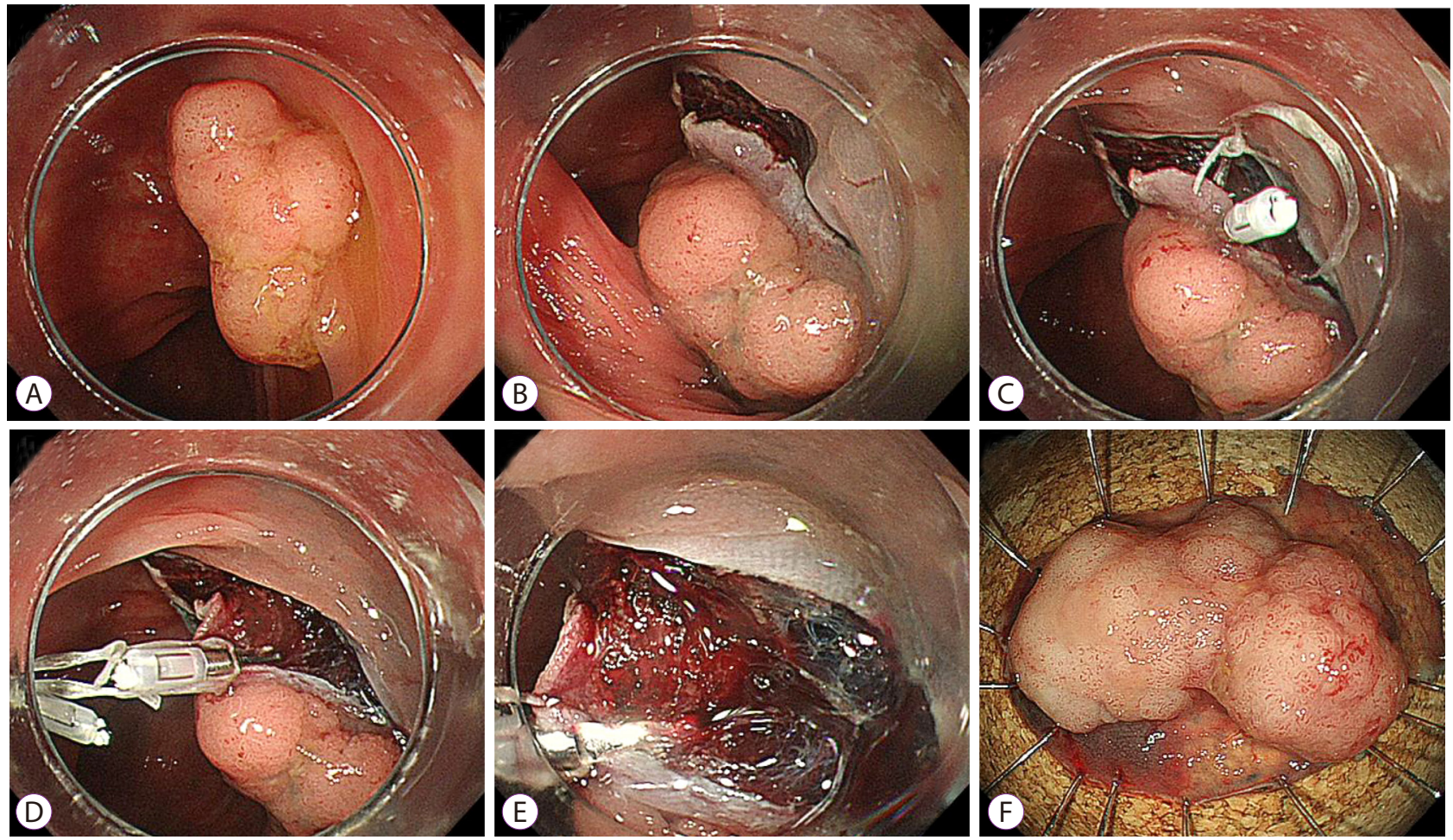

Fig. 3. Endoscopic images of colonic endoscopic submucosal dissection using clip-with-loops method. (A) An early adenocarcinoma $25 \mathrm{~mm}$ in diameter in the transverse colon. (B) After the circumferential incision was performed, poor endoscopic maneuverability prevented the fine visualization of submucosal layer. (C) One side of the loop was anchored to the edge of the lesion using a clip. (D) Another clip was attached to the opposite side of the colon wall while grasping the loop. (E) Good traction was produced, enabling a better submucosal view and safer dissection. (F) En bloc resection was performed.

Table 1. Characteristics and Results of Traction Methods for Colorectal Endoscopic Submucosal Dissection

\begin{tabular}{|c|c|c|c|c|c|c|c|c|}
\hline & $n$ & $\begin{array}{l}\text { Lesion size } \\
\text { (Mean, mm) }\end{array}$ & $\begin{array}{c}\text { Procedure } \\
\text { time } \\
\text { (Mean, min) }\end{array}$ & $\begin{array}{c}\text { En bloc } \\
\text { resection } \\
(\%)\end{array}$ & $\begin{array}{l}\text { Adversed } \\
\text { event }\end{array}$ & $\begin{array}{l}\text { Special } \\
\text { devices }\end{array}$ & $\begin{array}{l}\text { Reinsertion } \\
\text { of endoscope }\end{array}$ & Limitations \\
\hline External forceps & 13 & 33 & 60 & 100 & $1^{\text {a) }}$ & Required & Needed & Only for rectal lesions \\
\hline Modified clip-with-line & 23 & 27 & 61 & 100 & $1^{\mathrm{a})}$ & Not required & Not needed & \\
\hline $\begin{array}{l}\text { Clip-and-snare with a } \\
\text { prelooping technique }\end{array}$ & 17 & 32.5 & 45.6 & 100 & $1^{\text {a) }}$ & Not required & Needed & $\begin{array}{l}\text { Overtube is required } \\
\text { for deep colon lesions }\end{array}$ \\
\hline S-O clip-assisted & 27 & 33.5 & 37.4 & 100 & 0 & Required & Not needed & \\
\hline Ring-shaped thread & 21 & $\mathrm{n} / \mathrm{a}$ & $80^{\mathrm{b})}$ & $\mathrm{n} / \mathrm{a}$ & 0 & Not required & Not needed & \\
\hline
\end{tabular}

n/a, not available.

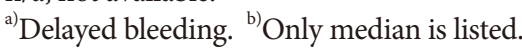


The results of a retrospective and a prospective study and characteristics of each method are listed in Table 1. Overall, these techniques achieve sufficiently favorable results in procedure time, en bloc resection rate, and adverse event rate. Although, from a technical aspect, each technique has advantag-

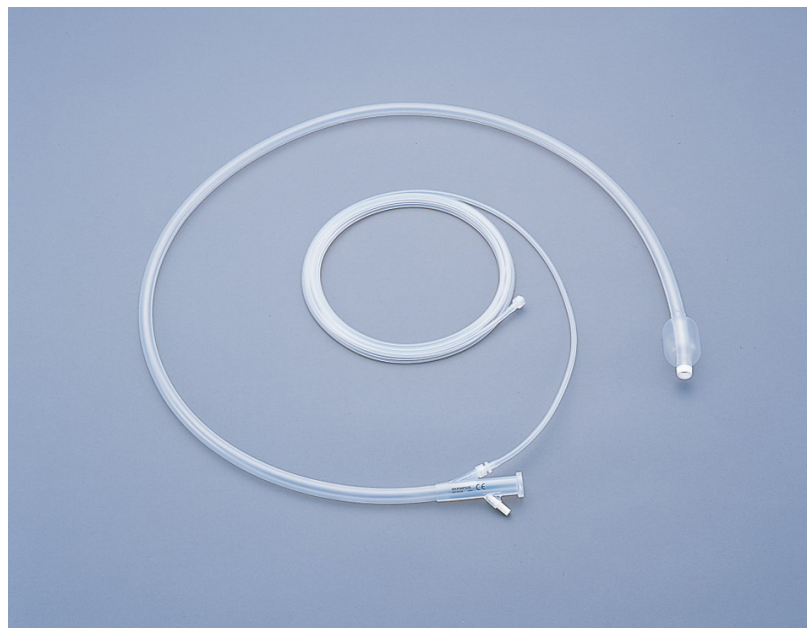

Fig. 4. Overtube with balloon. A picture of the ST-SB1 (Olympus, Tokyo Japan) is shown. The inflated balloon improves scope stability and maneuverability during procedures.

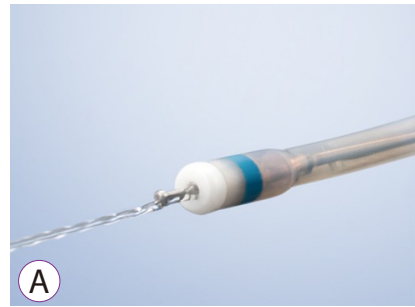

(B)
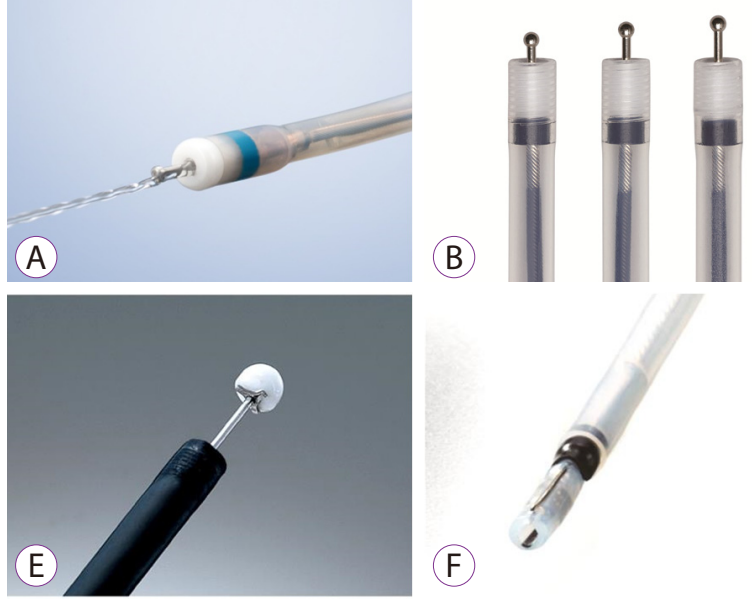

( es and disadvantages. Proper application of these methods, in accordance with the site of lesion or the clinical presentation can contribute to more effective and safer colorectal ESD.

\section{NEW DEVICES}

\section{Overtube with balloon}

The colon is sometimes tortuous and angulated, which may cause difficulty inserting the scope to the target lesion or stabilizing the scope during the ESD procedure. To overcome these difficulties, a singleballoon (Olympus, Tokyo, Japan) or doubleballoon (Fujifilm, Tokyo, Japan) endoscopy system (Fig. 4) can be used. However, only a limited number of advanced hospitals are equipped with these long, specialized endoscopes. In 2009, Ohya et al. ${ }^{24}$ reported the usefulness of a balloon overtube-guided colorectal ESD. They utilized a single-balloon overtube designed for enteroscopy and shortened to $70 \mathrm{~cm}$ (ST-SB1, $13.2 \mathrm{~mm}$ outer diameter, $11 \mathrm{~mm}$ inner diameter, and 1,400 $\mathrm{mm}$ total length; Olympus) with a thin diagnostic gastroscope (GIF-Q260, $9.2 \mathrm{~mm}$ outer diameter; Olympus) which can be inserted through the narrow lumen of ST-SB1. They found this method to be effective with an
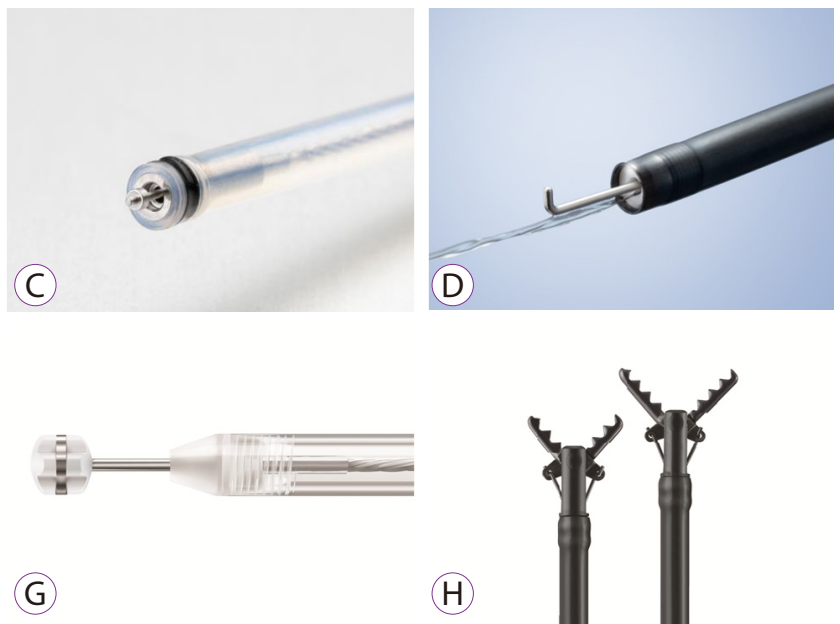

(H)

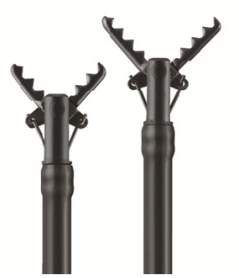

\begin{tabular}{|c|c|c|c|c|c|c|c|}
\hline (A) & (B) & (C) & (D) & (E) & (F) & (G) & $(\mathrm{H})$ \\
\hline Dual Knife J & Flush Knife BT-S & Splash M Knife & Hook Knife J & IT Knife2 & Mucosectom & SAFE Knife & Clutch Cutter \\
\hline Olympus & Fujifilm & Pentax & Olympus & Olympus & Pentax & Fujifilm & Fujifilm \\
\hline \multicolumn{4}{|c|}{ Needle-type knife } & IT knife & \multicolumn{2}{|c|}{ non-IT type knife } & Scissors type \\
\hline knob-shaped tip & ball-tip & disk-tip & L-shaped hook & & & & scissor forceps \\
\hline water-jet & water-jet & water-jet & water-jet & - & - & - & - \\
\hline
\end{tabular}

Fig. 5. Electrosurgical knives for endoscopic submucosal dissection. 

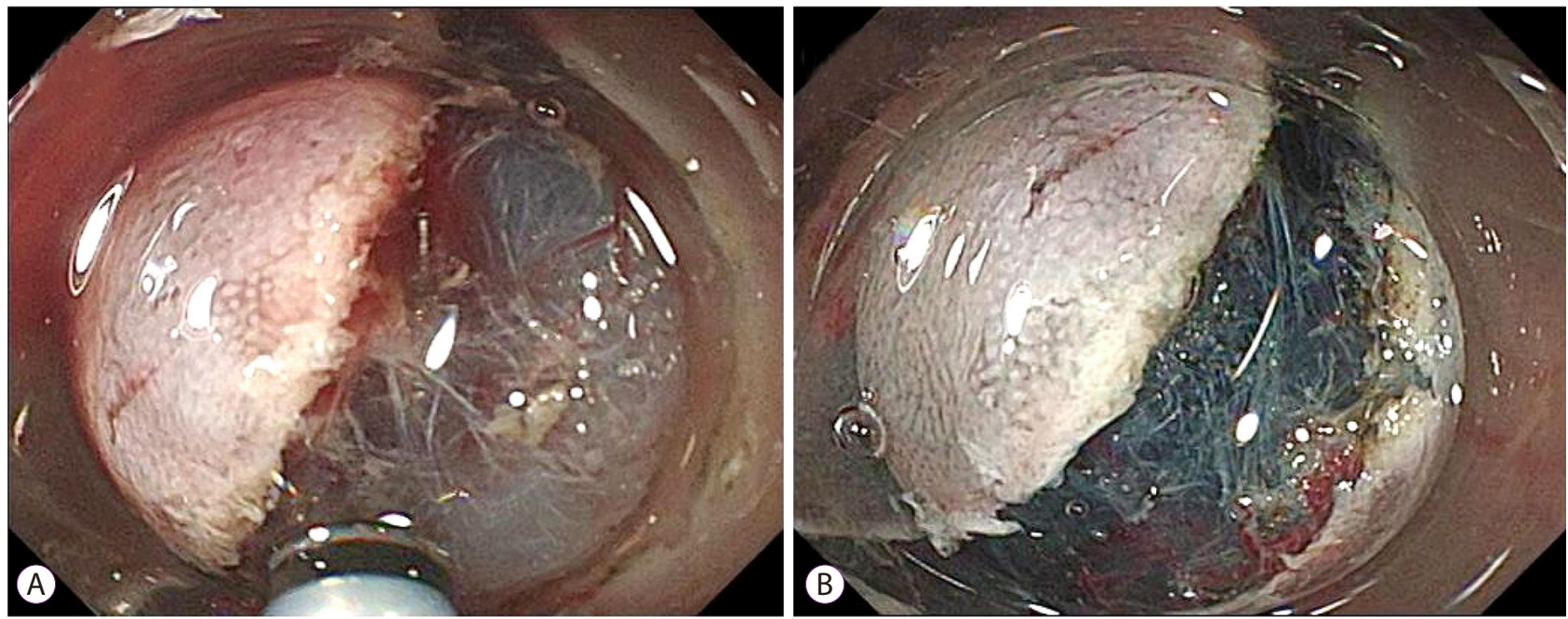

Fig. 6. Submucosal injection using water-jet function of the Splash M knife. (A) After mucosal incision, the submucosal layer was found to be too thin for a safe dissection. The tip of the Splash M knife (shown in the bottom of the image) was put on the submucosal layer for water-jet injection. (B) After injection, the thickened submucosal layer was effectively visualized.

86.7\% (13/15) en bloc resection rate without perforation. Although, there still were issues in terms of the limitations of the devices. In 2012, Okamoto et al. ${ }^{25,26}$ reported that a prototype of the short and large-diameter balloon overtube designed for colonoscopy (ST-Y0001-3C1; Olympus), which fits a single channel water-jet colonoscope (PCF-260J; Olympus), could be used for a colorectal ESD. Recently, a large-diameter balloon overtube (ST-CB1, $16.2 \mathrm{~mm}$ outer diameter, $13.8 \mathrm{~mm}$ inner diameter, and $770 \mathrm{~mm}$ total length; Olympus) was developed. This new splinting tube can improve poor scope maneuverability during ESD in the proximal colon (Asayama et al. ${ }^{27}$ ) and may enable the wide-spread use of balloon-assisted colorectal ESD even in general hospitals.

\section{Electrosurgical knives with water-jet function}

Since an insulation-tipped diathermic knife (IT knife) (KD610; Olympus) started to be used for gastric ESD, several kinds of electrosurgical knives have been developed and improved for safe and effective ESD (Fig. 5). Needle-type knives may be currently the most frequently chosen devices which can be used for marking, mucosal incision, dissection, and hemostasis during colorectal ESD. Devices of this type include the Flex knife (KD-630; Olympus), the Dual knife (KD-650; Olympus), the Hook knife (KD-260; Olympus), and the B-knife (Zeon Medical, Tokyo, Japan). Mucosectom (Pentax, Tokyo, Japan) and SAFEKnife (Fujifilm) are knives where the tip consists of a combination of an insulator and a conductor. Scissor type knives including the Clutch Cutter (Fujifilm) and the SB Knife (Sumitomo Bakelite, Tokyo, Japan) can grasp the targeted submucosal tissue and dissect while confirming the cutting line.

The electrosurgical knife with water-jet function is a newly developed device that can produce a jet of water from its tip. This enables submucosal injection of saline without replacing devices (Fig. 6). Takeuchi et al. ${ }^{28}$ reported the usefulness of the Flushknife (DK2618JN; Fujifilm), an endo-knife with a water-jet function, compared with the Flex knife (KD-630; Olympus) in terms of mean procedure time (61.0 [49.3-72.7] min vs. 87.3 [71.3-103.4] min, $p=0.02$ ). Furthermore, other knives which have the same function were developed, such as the Hook knife J (KD-625; Olympus), the Triangle-tip knife J (KD-640; Olympus), and the Dual knife J (KD-655; Olympus). The Splash M knife (DN-D2718B; Pentax) has a metal disk, 0.8 $\mathrm{mm}$ in diameter, which enables effective cutting of the mucous layer and stabilizes the device during dissection. When retracted, the electrical current spreads to the surrounding metal sheath, which is $1.8 \mathrm{~mm}$ in diameter, enabling effective hemostasis over a wide area. Sakaguchi et al. ${ }^{29}$ reported the usefulness of the Splash M knife with a resection speed of $15.5 \pm 7.3 \mathrm{~mm}^{2} / \mathrm{min}$ and an en bloc resection rate of $100 \%(15 / 15)$ with no perforations. These results were achieved even when used by endoscopists in training.

\section{CONCLUSIONS}

Colorectal ESD is becoming a reliable and safe procedure because of these novel techniques and devices. Although, an adequate understanding of the characteristics of each technique and device is required for proper application. Further development and improvement of these strategies are expected to facilitate widespread use of colorectal ESD not only in Asian countries, but also in the Western world. 


\section{Conflicts of Interest}

Mitsuhiro Fujishiro declares that he received a collaborative fund for the development of the Splash M knife from HOYA-Pentax as a chief investigator of the University of Tokyo. The other authors declare that they have no conflicts of interest.

\section{REFERENCES}

1. Hosokawa K, Yoshida S. [Recent advances in endoscopic mucosal resection for early gastric cancer]. Gan To Kagaku Ryoho 1998;25:476-483.

2. Ono H, Kondo H, Gotoda T, et al. Endoscopic mucosal resection for treatment of early gastric cancer. Gut 2001;48:225-229.

3. Nakajima T, Saito Y, Tanaka S, et al. Current status of endoscopic resection strategy for large, early colorectal neoplasia in Japan. Surg Endosc 2013;27:3262-3270.

4. Saito Y, Uraoka T, Yamaguchi Y, et al. A prospective, multicenter study of 1111 colorectal endoscopic submucosal dissections (with video). Gastrointest Endosc 2010;72:1217-1225.

5. Hayashi Y, Sunada K, Takahashi H, et al. Pocket-creation method of endoscopic submucosal dissection to achieve en bloc resection of giant colorectal subpedunculated neoplastic lesions. Endoscopy 2014;46 Suppl 1 UCTN:E421-E422.

6. Hayashi Y, Miura Y, Yamamoto H. Pocket-creation method for the safe, reliable, and efficient endoscopic submucosal dissection of colorectal lateral spreading tumors. Dig Endosc 2015;27:534-535.

7. Sakamoto H, Hayashi Y, Miura Y, et al. Pocket-creation method facilitates endoscopic submucosal dissection of colorectal laterally spreading tumors, non-granular type. Endosc Int Open 2017;5:E123-E129.

8. Imaeda $\mathrm{H}$, Iwao $\mathrm{Y}$, Ogata $\mathrm{H}$, et al. A new technique for endoscopic submucosal dissection for early gastric cancer using an external grasping forceps. Endoscopy 2006;38:1007-1010.

9. Imaeda H, Hosoe N, Ida Y, et al. Novel technique of endoscopic submucosal dissection using an external grasping forceps for superficial gastric neoplasia. Dig Endosc 2009;21:122-127.

10. Imaeda $\mathrm{H}$, Hosoe $\mathrm{N}$, Ida $\mathrm{Y}$, et al. Novel technique of endoscopic submucosal dissection by using external forceps for early rectal cancer (with videos). Gastrointest Endosc 2012;75:1253-1257.

11. Oyama T. Counter traction makes endoscopic submucosal dissection easier. Clin Endosc 2012;45:375-378.

12. Oyama T. Endoscopic submucosal dissection using a hook knife. Tech Gastrointest Endosc 2011;13:70-73.

13. Yamasaki Y, Takeuchi Y, Hanaoka N, et al. A novel traction method using an endoclip attached to a nylon string during colonic endoscopic submucosal dissection. Endoscopy 2015;47 Suppl 1 UCTN:E238-E239.

14. Yamasaki Y, Takeuchi Y, Uedo N, et al. Traction-assisted colonic endoscopic submucosal dissection using clip and line: a feasibility study. Endosc Int Open 2016;4:E51-E55.
15. Yoshida N, Doyama H, Ota R, Tsuji K. The clip-and-snare method with a pre-looping technique during gastric endoscopic submucosal dissection. Endoscopy 2014;46 Suppl 1 UCTN:E611-E612.

16. Ota R, Doyama H, Tsuji K, Yamada S. Deep colonic endoscopic submucosal dissection using a modified clip and snare method incorporating a pre-looping technique. BMJ Case Rep 2015;2015.

17. Yamada S, Doyama H, Ota R, et al. Impact of the clip and snare method using the prelooping technique for colorectal endoscopic submucosal dissection. Endoscopy 2016;48:281-285

18. Sakamoto N, Osada T, Shibuya T, et al. The facilitation of a new traction device (S-O clip) assisting endoscopic submucosal dissection for superficial colorectal neoplasms. Endoscopy 2008;40 Suppl 2:E94-E95.

19. Sakamoto N, Osada T, Shibuya T, et al. Endoscopic submucosal dissection of large colorectal tumors by using a novel spring-action S-O clip for traction (with video). Gastrointest Endosc 2009;69:1370-1374.

20. Ritsuno H, Sakamoto N, Osada T, et al. Prospective clinical trial of traction device-assisted endoscopic submucosal dissection of large superficial colorectal tumors using the S-O clip. Surg Endosc 2014;28:31433149

21. Osada T, Sakamoto N, Shibuya T, et al. "Loops-attached rubber band" facilitation of endoscopic submucosal dissection of superficial colorectal neoplasm. Endoscopy 2008;40 Suppl 2:E101-E102.

22. Tomiki Y, Ishiyama S, Sugimoto K, et al. Colorectal endoscopic submucosal dissection by using latex-band traction. Endoscopy 2011;43 Suppl 2 UCTN:E250-E251.

23. Mori H, Kobara H, Nishiyama N, Fujihara S, Matsunaga T, Masaki T. Novel effective and repeatedly available ring-thread counter traction for safer colorectal endoscopic submucosal dissection. Surg Endosc 2017;31:3040-3047.

24. Ohya T, Ohata K, Sumiyama K, et al. Balloon overtube-guided colorectal endoscopic submucosal dissection. World J Gastroenterol 2009;15:6086-6090

25. Okamoto K, Muguruma N, Kitamura S, et al. A new large-diameter overtube for endoscopic submucosal dissection in the colon. Endoscopy 2012;44 Suppl 2 UCTN:E395-E396.

26. Okamoto K, Muguruma N, Kitamura S, Kimura T, Takayama T. Endoscopic submucosal dissection for large colorectal tumors using a cross-counter technique and a novel large-diameter balloon overtube. Dig Endosc 2012;24 Suppl 1:96-99.

27. Asayama N, Oka S, Tanaka S, et al. Clinical usefulness of a single-use splinting tube for poor endoscope operability in deep colonic endoscopic submucosal dissection. Endosc Int Open 2016;4:E614-E617.

28. Takeuchi Y, Uedo N, Ishihara R, et al. Efficacy of an endo-knife with a water-jet function (Flushknife) for endoscopic submucosal dissection of superficial colorectal neoplasms. Am J Gastroenterol 2010;105:314-322.

29. Sakaguchi Y, Tsuji Y, Fujishiro M, et al. Evaluation of endoscopic submucosal dissection using a new endosurgical knife DN-D2718B: a first clinical feasibility study. Endosc Int Open 2017;5:E670-E674. 